\title{
FOLFOX/Panitumumab Regimen
}

National Cancer Institute

\section{Source}

National Cancer Institute. FOLFOXIPanitumumab Regimen. NCI Thesaurus. Code C136247.

A chemoimmunotherapy regimen consisting of leucovorin, fluorouracil and oxaliplatin (FOLFOX), plus panitumumab that is used for the treatment of colon cancer. 